\section{Reporting on suicide in Malaysia: Problem characterization and solution advocacy by media}

KOME - An International Journal of Pure Communication Inquiry

Volume 9 Issue 2, p. 46-64. (C) The Author(s) 2021

Reprints and Permission: kome@komejournal.com

Published by the Hungarian

Communication Studies Association DOI: $\underline{10.17646 / K O M E .75672 .66}$

\author{
Yang Lai Fong \\ Department of Journalism, Xiamen University Malaysia, MALAYSIA
}

\begin{abstract}
Rising incidents of suicide capture the attention of healthcare providers, government agencies, non-governmental organizations and media. Furthermore, public conversations about social problems are largely mediated by the media. It is noteworthy that media have the power to shape the way the public thinks about an issue by suggesting what the issue is about, what the cause is, and what should be done as a solution. The current study aims to examine suicide coverage in Malaysia, particularly the problem characterization and solution advocacy by The Star in reporting suicide from 2014 to 2018. The Star is the English-language daily newspaper with the largest circulation in Malaysia. Through content analysis, the study found that there was a statistically significant difference between the number of articles reporting suicide and the different years. Most of the coverage was published in the form of straight news with a negative depiction of suicide. There was reporting on both local and international suicide news. In addition, suicide was linked to various issues (e.g. mental health, relationship or marriage problems, financial problems, workplace stress, etc.) in the coverage. The study also found a significant difference between issue narrative styles and suicide solutions. The practical implications of the findings are discussed with regard to the role of media in raising awareness of suicide, promoting prevention and intervention efforts at the institutional level, as well as undertaking a more robust interpretive approach in addressing the issue.
\end{abstract}

Keywords: suicide, mental health, social problem, framing, content analysis

\title{
Introduction
}

The news media are important platforms where complex social problems are presented, discussed and defined. In addition, media are also important venues where various issue solutions are often suggested and debated. It has been well documented in literature that news frames play a significant role in influencing readers' interest, attention, interpretation and comprehension of the news (Scammell \& Semetko, 2018).

Since Shanto Iyengar's (1990) study of responsibility framing and Bernard Weiner's (1995) work on attribution theory, a significant amount of communication research has investigated how society attributes responsibility for social problems (Kim, 2015). These studies particularly focused on examining societal- and personal-level consequences of the responsibility attribution. In addition, Liu, Robinson and Vedlitz (2016) saw a growing body 
of literature that extensively examined the dynamics of problem characterization in politics and policy processes. The authors mentioned that problem characterization is also known as problem definition, issue framing or issue attributes. They further outlined four dimensions of problem characterizations, namely issue image, issue scope, issue linkage and issue narrative style. It was suggested that these problem characterizations influenced how problem solutions are generated in media.

In news reporting, which topics were covered (or not) and how they were covered were influenced by many considerations, including law, economics, political forces, power relations, culture, race, the organizational structure of media and work routines of journalists (Wichgers, Jacobs \& van Spanje, 2020). von Sikorski (2020) also recognized that framing analysis allows researchers to examine the roles of media in the development of social and political issues. It is noteworthy that attribution of responsibility is a social attitude that shapes individuals' issue opinions, political attitudes and behaviors (Brownell et al., 2009). More importantly, attribution of responsibility is an important target of change, especially in identifying problem solutions or issue prevention, intervention and treatment (Hernandez-Aquado \& Chilet-Rosell, 2020).

Suicide is an international public health problem, more than 800,000 people are dying by suicide worldwide every year. Suicide is also among the top 10 causes of death in the world and is the second biggest cause of death amongst those aged between 15 and 29 (World Health Organization, 2017). In Malaysia, there has been a 60\% increase in suicide cases in the past 45 years according to the Malaysian Psychiatric Association statistics. It was estimated that seven people would attempt suicide daily in the country. Furthermore, previous studies also indicated that 13 out of every 100,000 people die from suicide a year in Malaysia (Indramalar, 2018).

It is important to note that Malaysia is a country with a Muslim majority for whom attempted suicide is a serious breach of the faith (a grievous sin). Furthermore, those who survive a suicide attempt in the country may be prosecuted under Section 309 of the Penal Code, which allows punishment up to a year in jail, a fine, or both (Zolkepli, 2020). In 2019, the then de facto law minister Liew Vui Keong announced that the Attorney General's Chambers was studying possible amendments to laws related to suicide. It was also mentioned that there would be consultations with several ministries, police, Fire and Rescue Department, Department of Islamic Development, and Malaysian Psychiatric Association (Pandiyan, 2020).

Considering the influence of media in reporting social issues, as well as the severity of suicide in both Malaysia and globally, it is important to understand how the media frame responsibility for suicide. However, this knowledge is largely missing from current scholarship, as existing research has primarily focused on the copycat or prevention effects of suicide coverage by the media. Also, research examining how Malaysian news media report about suicide is relatively scarce (e.g. Chan, Ibrahim, Rahman, Bartlett, Ping \& Nordin, 2018; Johari et al., 2017; Victor, Heng, Govindaraju, Tan, Rajaratnam \& Yang, 2019), and neither of these studies examined responsibility framing of suicide in the country. Therefore, the current study attempted to fill this gap by employing the framing and attribution theory to examine the problem characterization and solution advocacy by media in reporting suicide.

Specifically, the study seeks to answer the following research questions:

RQ1: What was the issue image of suicide presented by the media?

RQ2: What was the issue scope of suicide reported by the media?

RQ3: What was the issue linkage of suicide portrayed by the media?

RQ4: What was the issue narrative style used by the media in reporting suicide?

RQ5: What was the solution advocated by the media in reporting suicide?

RQ6: What was the association between issue narrative style and solution advocated by the media in reporting suicide? 


\section{Framing theory}

The origins of the framing concept lie in the fields of cognitive psychology and anthropology. Subsequently, it was adopted, often with a shift in meaning, by other disciplines, including sociology, economics, linguistics, social-movements research, policy research, communication science, political communication, public relation research and health communication (Bryant and Miron, 2004). Gaye Tuchman (1978) and Todd Gitlin (1980) were credited as the two scholars who expanded the application of framing into journalism studies.

According to Chong and Druckman (2007), communication scholars generally use the term "frame" in two ways. First, a media frame refers to the words, images, phrases and presentation styles that a media outlet uses when relaying information about an issue or event to an audience. The chosen frame reveals what the media outlet sees as important to the topic reported. Scheufele and Tewksbury (2007) regarded this way of framing as a macro-level construct. Entman's (1993, p. 52) definition of framing falls into this category, whereby framing means "to select some aspects of a perceived reality and make them more salient in a communicating text, in such a way as to promote a particular problem definition, causal interpretation, moral evaluation, and/or treatment recommendation for the item described".

In addition, Tankard, Hendrickson, Silberman, Bliss and Ghanem (1991, p. 9) considered media frame as "the central organizing idea for news content that supplies a context and suggests what the issue is through the use of selection, emphasis, exclusion, and elaboration." McCombs (1997, p. 143) also described framing as "the selection of a restricted number of thematically related attributes for inclusion in the media agenda when a particular object is discussed."

Secondly, a frame of thought or an individual frame is another way of how communication scholars use the word "frame". It refers to an individual's cognitive understanding of a given situation (Chong and Druckman, 2007). Unlike a media frame that reflects a media outlet's emphasis, frames in thought refer to what an audience member believes to be the most salient aspect of an issue. It is considered as a micro level construct (Scheufele \& Tewksbury, 2007) as well as a media effects approach (Scheufele, \& Scheufele, 2010).

In the micro level construct approach, scholars have been using the concept of frame to refer to schemas (Wood, Stoltz, Van Ness and Taylor, 2018). Goffman's (1974, p. 21) defined frames as "schemata of interpretation that enable individuals to understand certain events and to locate, perceive, identify and label occurrences". Reese, Gandy Jr and Grant(2001, p. 14) also posited that "frames may best be viewed as an abstract principle, tool, or schemata of interpretation that works through media texts to structure social meaning". Significantly, Scheufele (2004, p. 411) summarized that the effects of media framing can be divided into four categories:

1. Audience schemas can be activated because individuals deem these schemas applicable to the frame(s) that they encounter (activation or applicability effect).

2. Audience schemas can be modified by media framing (transformation effect).

3. If there is no schema available, cumulative and consonant media framing can establish such a schema (establishing effect).

4. Media framing can alter recipients' attitudes or opinions (attitudinal effect).

In addition, Iyengar's (1990) research showed that when a social issue such as poverty was portrayed via a thematic frame (i.e., depicting the general context and conditions of an issue), government and society at large were seen as at fault and consequently held accountable. In contrast, when an episodic frame (i.e., presenting an issue through individual stories) was used to feature a personal story, individuals were blamed for their own situations. In his work, 
Iyengar also differentiated causal responsibility, which "focuses on the origin of the problem," from treatment responsibility, which is about "who or what has the power either to alleviate or to forestall alleviation of the problem" (p. 879). Entman (1993) expanded the above definition by delineating the components of a frame: causal attribution (who or what is responsible for causing the issue), the definition of an issue (consequences of causal agents' actions), moral judgments (evaluation of causal agents and their actions) and treatment responsibility (who or what can best resolve the issue).

According to Iyengar (2005), communication researchers have identified two distinct types of media framing effects: equivalency framing and emphasis framing. In equivalency framing, objective equivalent information is presented in positive versus negative, and certainty versus probability language. Emphasis framing includes a range of perspectives or considerations in the coverage of a topic or issue. Consequently, frames give emphasis to some aspects of the topic, making certain interpretations more salient in audience cognition. In health communication, most framing research has focused on examining the effects of equivalence framing (i.e., gain vs. loss frames) on compliance with recommended health behaviors (Sun, Krakow, John, Liu \& Weaver, 2016). The purpose of this line of framing research is to examine the persuasive efficacy of gain versus loss frames on different types of desired health behaviors (i.e., prevention and detection behaviors).

\section{Attribution theory}

Attribution theory was suggested by Heider (1958), and subsequently improved and expanded by Kelley (1967) and Weiner (1979). The theory postulates that individuals use available information to identify the causes of their own and others' behavior (Wallace, 2019). Internal attribution refers to the tendency to believe that behavior is caused by personality, disposition, beliefs or other internal factors. In contrast, external attribution is the inclination to assume that behavior is caused by environmental or situational factors (Liu, Cui, Zhang, Xia, Chen \& Skitmore, 2020). In general, individuals tend to attribute their behavior to external causes and the behavior of others to internal causes (Wallace, 2019).

In his study about negative public perceptions of juvenile diabetics, Vishwanath (2014) mentioned that attribution theory explains the phenomenon of stigma as a socio-cognitive process stemming from the need to make sense and infer a cause for events. The author also discussed three attributional dimensions that could influence public stigma: 1) locus of causal responsibility, 2) perceived curability or severity of a disease, and 3) temporal stability or reoccurrence.

Locus of responsibility can be further divided into two aspects: controllability and biological basis of diseases. In controllability, behaviors that are thought to be within the control of individuals are more prone to being stigmatized. This applies to illnesses like AIDS, child abuse, drug abuse and obesity. Vishwanath (2014) addressed that such beliefs within individualist cultures such as that of the US are thought to be founded on traditional conservative values of self-determination, individualism, internal control and self-discipline. In their framing analysis of obesity and policy support, McGlynn and McGlone (2018) found that internal cause attributions for obesity (e.g., lack of motivation to exercise) are negatively associated with support for public obesity policies. Conversely, external attributions for the obesity epidemic (e.g., food companies and restaurants make too much unhealthy food) are positively associated with support for the implementation of public policies.

In addition, diseases that have a biological basis (e.g. blindness, cancer, heart disease, etc.) are less likely to be stigmatized, less likely to lead to an emotional state of anger or hostility. 
On the contrary, sicknesses that have a biological basis tend to generate more empathy and consequently more helping behaviors toward the target individual.

The second attributional dimension that could influence public stigma is the perceived curability or severity of a disease. Diseases that are thought to be completely curable and perceived as being under the control of the individual are more prone to being stigmatized (Vishwanath, 2014). Individuals who suffer over a long time from curable or reversible diseases are perceived to be weak or noncompliant. In contrast, illnesses that are incurable and biologically caused are less likely to be judged because they engender sympathy toward the patients. It was mentioned that diseases such as migraines, obesity and substance abuse are more likely to be stigmatized because they are considered reversible while terminal cancer is less likely to be stigmatized (Turosak \& Siwierka, 2021).

The last attributional dimension outlined by Vishwanath (2014) is temporal stability or reoccurrence. Sicknesses that are considered as being rare and uncertain are expected to be more stigmatized than those that are common, predictable and reoccur. This is because the consistency of occurrence makes such diseases seem less threatening. Moreover, Vishwanath (2014) cited the optimistic bias theory to explain the phenomenon, whereby people tend to anticipate negative events to happen to others but not to themselves. Thus, people with a rare disease are more likely to be stigmatized because they are perceived to be weaker or inferior. Vishwanath (2014) also stated that beliefs about mental illness being rare and unpredictable significantly predict stigma toward people with mental health issues.

Moreover, Gounder and Ameer (2018) posited that attributions of health issues derive from three framing pathways, namely behavioral, medical and structural. Behavioral and medical frames emphasize individualized causal and treatment attributions by using exemplars living with the issue's consequences, while the structural frame considers social and environmental determinants. The authors also pointed out that individualized behavioral and medical frames are pervasive in health discourse. Concerns with the high use of these individualized frames, Gounder and Ameer (2018) addressed that they are tied to the perpetuation of blame and stigma attribution through the causal and treatment attributions. This is because neither the behavioral nor the medical frame addresses systemic problems, which seek to eliminate root causes of societal health issues. In contrast, the third pathway, structural frame (also referred to as societal frame), takes a wider lens, situating human agency within individuals' socio-economic and environmental constraints, which impact the availability and affordability of health-related choices and may even undermine what actions individuals can take in fixing the problem.

In their examination of the framing contest between food and marketing industries and public health groups at the New Zealand inquiry into obesity, Jenkin, Signal and Thomson (2011) found that the food and marketing industries framed obesity as a consequence of poor lifestyle choices. It was also attributed to factors like personal knowledge, cultural or other character deficits. In addition, the food and marketing industries claimed that lack of physical activity rather than increased food consumption was the dominant cause of obesity. However, obesity was considered as an effect of an obesogenic environment by public health groups. It was explained that the pervasive marketing and availability of low-cost, energy-dense/nutrientpoor foods have contributed to an obesogenic environment. While the food and marketing industries stressed on education as the key solution to obesity, public health groups called for regulation of the activities of the industries, and policies to address wider determinants of health and social inequalities. 


\section{Framing public health issues}

\section{Issue image}

By offering a typology of problem characterizations, Liu, Robinson and Vedlitz (2016) stated that issue image is the overall and fundamental impression of whether an issue involves potential stakes of causing harm or providing assistance. The concept of issue image is related to equivalency framing as well as what Manheim (1994) called "valence" in frame analysis. In other words, issue image means presenting information in positively versus negatively valenced language. In addition, Yang (2020) also explained that valence is the tone, slant or attitude of a news story, or comment regarding certain frames. By displaying the value of the statement or with positive and/or negative factors, the valenced news frame indicates the degree of the favorable or unfavorable influence of the coverage on the event/issue (Yang, 2020).

Specifically, loss-framed messages are more effective when promoting illness-detecting (screening) behaviors, while gain-framed messages are more effective when promoting health affirming (prevention) behaviors (Sun, Krakow, John, Liu \& Weaver, (2016).

\section{Issue scope}

Issue scope refers to how an issue may have a broad or narrow range of effects at various levels of the policymaking system (Liu, Robinson \& Vedlitz, 2016). It could be local, state, national or international level that can ultimately be tied to issue responsibility and policy jurisdiction. Furthermore, issue scope is also about issue ownership. It connects to different levels of policy authority, which affects what institutions and participants considered legitimate for having jurisdiction over the issue and possible solutions.

Traditionally, issue ownership posits that political parties hold reputations for their ability to handle certain issues. For example, Democrats in the US have been considered to be better at dealing with education, while Republicans have a better reputation in lowering taxes (Guo \& Vargo, 2015). In their analysis of issue ownership and policy communication, Dahlberg and Martinsson (2015) recorded that the topic of issue ownership has not received much attention. It was mentioned that research questions such as where issue ownership comes from, how it changes and how it is maintained have received only limited attention, while at the same time being fundamental for understanding the logic behind party competition and electoral choices.

\section{Issue linkage}

Issue linkage is defined as the association of a specific public problem with other public issues (Liu, Robinson \& Vedlitz, 2016). In other words, it is about which policy domain to which a specific issue is attached. Suicide is often associated with depression, while depression could be triggered by a wide array of biological, physical, environmental, socioeconomic and cultural conditions that interact in complex ways to contribute to its onsets and recurrences (Halladay, Munn \& Boyle, 2020).

It is important to note that Arafat, Menon and Kar (2021) highlighted that suicide in Southeast Asia differs from the West in several aspects. These include the lack of a bonafide mental illness in a significant proportion of those who took their life, the lower male-to-female gender ratio and the greater elderly to non-elderly suicide ratio. The authors addressed that the major drivers of suicide in the region include socioeconomic factors such as social inequities, gender disparities, financial strife and family conflicts.

Significantly, Hjelmeland and Knizek (2017) criticized that one of the most wellestablished truths in Western suicidology is that almost all (90\% or more) of those who die by 
suicide suffered from one or more mental disorders. The main evidence base for this $90 \%$ statistic is a series of psychological autopsies, in which psychiatric diagnoses have been assigned to the deceased by means of interviewing a few of the bereaved, often many years after the suicide. This statistic has been constantly repeated in academic literature, in suicide prevention strategies, as well as in the media.

While questioning the reliability and validity of the method used in establishing the $90 \%$ statistic, Hjelmeland and Knizek (2016) addressed that there may be a strong association between suicide and mental disorders but the authors stressed that "association is not cause" (p. 357). Moreover, Hjelmeland and Knizek (2017) argued that the discourse on the relationship between mental disorders and suicide is permeated with ideology, politics, and power positioning suicide as a predominately biomedical or psychiatric issue. It was revealed that critical voices and arguments were often dismissed as unsubstantiated opinions.

In addition, Hjelmeland and Knizek (2017) also pointed out that the suicidological field has been dominated by a narrow focus on risk factors, particularly mental disorders, with the linear cause-and-effect association. It was observed contended that there is even negative attitudes or prejudice toward qualitative research. Nonetheless, the authors claimed that qualitative research has found that complex contextual and existential issues (e.g. sociocultural context, the immediate social/relational circumstances, life course, etc.) are much more important to suicidality than mental disorders.

\section{Issue narrative style}

Issue narrative style is about whether the issue is portrayed as an episodic occurrence or a thematic concern. Episodic frame depicts a public problem in the form of a single, concrete instance, specific event or case (e.g., by reporting a specific suicide death). It usually focuses on hard news and tends to be more drama-oriented and visually compelling (Papacharissi \& de Fatima Oliveira, 2008). Furthermore, episodic framing is compatible with the economics of the news cycle because it requires less time and effort for background research and data collection than thematic framing (Zhang, Jin, Stewart \& Porter, 2016).

In contrast, thematic frame presents an issue within a broader context by providing more background information. It highlights the general connections between problems and encourages the understanding of public problems at a collective level, which is the societal, governmental or systemic level. In general, thematic framing approach presents the topic less descriptively and more analytically (Papacharissi \& de Fatima Oliveira, 2008). When reporting about suicide, a thematic frame might discuss national statistics related to the prevalence of suicide, whereby it looks into the influence of gender, religion, ethnicity, etc. Even though both episodic and thematic frames are distinct, scholars asserted that they are not mutually exclusive. In general, a news story contains both types of framing but typically one news frame exceeds the other (Iyengar, 1990, Papacharissi \& de Fatima Oliveira, 2008).

In their study about news media coverage of stakeholder views on suicide and its reporting in New Zealand, Jenkin, Slim and Collings (2020) recorded that the debate around suicide and its reporting were marked by the conflating of two different types of media reporting on suicide: 1) the reporting of individual suicide cases, 2) news media coverage of suicide as a public health issue. The first category of news is most likely to report suicide as an episodic occurrence while the latter is expected to adopt a thematic narrative style.

According to Starr and Oxlad (2020), framing research has found some variation depending on the health topic. For example, cardiovascular stories tend to focus more on scientific/medical information, whereas infectious disease outbreaks and cancer stories are likely to focus on an individual. Furthermore, research into the effects of framing on reader responses has also found differences between health topics. It was mentioned that mental illness is associated with more 
thematic comments, whereas obesity and personal health stories (such as nutrition) are associated with more episodic comments.

\section{Solutions advocacy}

Through analyzing news framing and attribution of responsibility, Kim (2015) found that liberal newspapers focused more than conservative papers on societal responsibilities. The author suggested that political orientations of newspapers could affect the media's attributions of responsibility. It was also mentioned that commercial pressure seemed to encourage news writers to frame a story with a human-interest or episodic angle, thereby diverting attention away from larger societal responsibilities.

While entertainment television was considered to be a medium for episodic framing (Barry, Brescoll \& Gollust, 2013), Iyengar (1990) stated that televised news reports focus on concrete acts or live events at the expense of general contextual material. It was mentioned that episodic reports do not require reporters with subject-matter expertise, and they are less likely to be criticized as biased by avoiding interpretive analysis. In addition, Iyengar (1996, p. 70) claimed that the dominant episodic frame used by television news tends to "reduce complex issues to the level of anecdotal cases, thus leading the audience to attributions that shield society and government from responsibility".

Furthermore, Wikler (2002) addressed that the American public health system has largely adopted an individualistic model by placing more causal and problem-solving responsibilities on individuals and privileging individual-oriented solutions such as encouraging behavioral changes and promoting the use of pharmaceuticals. This approach has been attributed partly to the individualistic cultural values prevalent in American society, and also to the biomedical explanation of causation for health problems. Another justification for the lack of societyoriented solutions is the potentially drastic and prohibitive changes in societal resource allocations that any social remedy requires, such as new regulations, taxes, and social services (Petticrew, Eastmure, Mays, Knai, Durand \& Nolte, 2013).

\section{Method}

The present study analyzed The Star, which is an English-language daily with the largest circulation in Malaysia. According to the Audit Bureau of Circulations Malaysia (Audit Bureau of Circulation Malaysia, 2019), the 2018 average daily circulation of The Star was 175,986. The major shareholder of The Star is the Malaysian Chinese Association (MCA), which is one of the component parties of Barisan Nasional (National Coalition). This means that MCA is a pro-government political party while The Star a pro-establishment newspaper (Yang, 2020).

The time frame of the study was 1 January 2014 to 31 December 2018 (five years). The study employed a purposive sample, whereby all articles mentioning "suicide" and all variations of the term (e.g., "killed himself or herself"; "shot himself or herself", "sudden death", "fell to death", "plunged to death", "jumped to death", "hung to death", "hanged to death"), which were found within headlines or body text were retrieved from The Star's database. Sometimes the same story was published in The Star but in different days, or in different focus or types of articles. These duplicate reports were included in the count of suicide reports because this study aimed to examine the frequency of reporting instead of the number of unique suicides. 


\section{Coding procedure}

Issue image refers to the overall portrayal of suicide. As mentioned earlier, the concept of issue image is related to "valence" in frame analysis. Valence/tone of the articles refers to the attitude expressed towards any individual, group, party, institution or topic by its author (Baumgartner and Wirth, 2012). Previous studies mostly employed the categories of negative/positive or critical/supportive in the examination of valence in news coverage (e.g. Holling, 2019; Naab et al., 2020). This study used the categories of negative, positive and neutral for the analysis of attitude expressed towards suicide. Only the most dominant issue image presented in the article was coded.

1. Negative - portrayed suicide as a severe social problem; conveyed an unfavorable impression towards suicide; criticized the act or intention of suicide; contained quotes by individuals who disapproved suicide; reported mourning of a person's death to reflect the pain suicide brought to families and friends while avoid glorifying suicide victims as objects of public adulation; reported injury of a person who attempted suicide; reported charge against a person who attempted suicide.

2. Positive - conveyed favorable impression towards suicide; supported the act or intention of suicide; glorified suicide victims as objects of public adulation; contained quotes by individuals who approved suicide.

3. Neutral - neither favorably nor unfavorably portrayed suicide case.

The examination of issue scope looked at whether the suicide reporting was discussed at one of the following levels:

1. Local -reported suicide cases that happened in Malaysia.

2. International - reported suicide cases that happened outside Malaysia.

Wimmer and Dominick (2013) stated that there are two ways to establish coding categories for content analysis. The first is known as priori coding, where the researcher establishes the categories before the data are collected, based on some theoretical or conceptual rationale. The second is called emergent coding, where the researcher establishes categories after a preliminary examination of the data. This study employed the emergent coding approach for examining issue linkage. Seven categories were established for the current study and all the reasons behind a suicide cited in an article were coded accordingly:

1. Mental health issues - reported about mental health problems (e.g. depression, bipolar affective disorder, schizophrenia, anxiety disorders, dementia, etc.) of the deceased or person who attempted suicide; discussed the connection between depression and suicide; addressed various topics related to depression and/or mental illness.

2. Relationship or marriage problems - reported about relationship or marriage problems faced by the deceased or person who attempted suicide.

3. Financial problems - reported about unemployment, debts or other financial challenges faced by the deceased or person who attempted suicide.

4. Workplace stress - reported about pressure, anxiety, worries or other harmful emotional responses towards job demand or workplace relationships faced by the deceased or person who attempted suicide.

5. Bullying or cyberbullying - reported about bullying or cyberbullying faced by the deceased or person who attempted suicide. 
6. Academic pressure - reported about examination pressure faced by the deceased or person who attempted suicide; reflected issues of high expectation from parents, teachers and schools.

7. Others - any content that could not fit the above six categories.

Narrative style was assessed under the rule of whether the story used an episodic or thematic framing approach. This study employed two categories for narrative style:

1. Episodic frame - predominantly depicted suicide in the form of a single, concrete instance or a specific event.

2. Thematic frame - predominantly presented suicide within a broader context; portrayed suicide in the form of general outcomes; reported national or international statistics related to the prevalence of suicide.

Emergent coding approach was also used in this study to develop the categories for solutions advocacy:

1. Individual responsibility - emphasized individual resilience and effort for one's own life and wellbeing.

2. Societal responsibility - called for parents and teachers to manage academic expectation towards students; advocated the need to prevent and intervene in cyberbullying by parents, teachers and policy-makers; stressed on the responsibility of corporations, financial institutions, traditional media, social media, etc. to address social and/or economic problems; urged the government to improve the healthcare system.

3. Combination - an almost equal mix of both individual and societal responsibility.

4. Not mentioned - no solution for suicide was mentioned in the article.

\section{Data analysis}

The 467 articles collected from The Star were analyzed using SPSS Statistics for Windows, Version 26.0. Descriptive statistics such as frequencies and percentages were used to summarize the data. In addition, one-way between-groups analysis of variance (ANOVA) was employed to test if there is a significant difference between the number of articles and different 1) years, 2) types of articles, and 3) problem characterizations. Also, Pearson Chi-Square Test was used to test if there is a significant difference between problem characterization and solution advocacy.

\section{Inter-coder reliability}

To ensure the reliability of this study, a communication graduate was chosen as the second coder. During the training session, the writer (who was also the first coder) and the second coder coded 50 articles that were chosen randomly from the sample of this study. Disagreements were analyzed and some additional explanations were included in the coding instruction in the codebook. Wimmer and Dominick (2013) suggested that between 10\% and $25 \%$ of the body of content should be tested. Therefore, the inter-coder reliability for this study was established by randomly selecting $10 \%$ of the news items, which was equivalent to 47 articles. Using Krippendorff's alpha, the inter-coder reliability for each coding category are 
issue image (0.973), issue scope (1.000), issue linkage (0.877), narrative style (0.916) and solutions advocacy (0.973).

\section{Findings}

Table 1 records the distribution of articles according to publication years. There was a statistically significant difference between the number of articles and different years as determined by one-way ANOVA $(\mathrm{F}(7,469)=27.333, p=.000)$. The highest number of articles reporting on suicide came from 2014, which was the year in which the late famous American actor and comedian Robin Williams died by suicide. Out of 169 articles that were reporting on suicide in 2014, $14.8 \%$ was about Robin Williams's passing as well as tributes to him.

Table 1. Number of Articles Reporting on Suicide by The Star from 2014-2018

\begin{tabular}{c|c|c}
\hline Year & Frequency & Percentage \\
\hline 2014 & 169 & 36.2 \\
2015 & 37 & 7.9 \\
2016 & 61 & 13.1 \\
2017 & 71 & 15.2 \\
2018 & 129 & 27.6 \\
\hline Total & 467 & 100.0 \\
\hline
\end{tabular}

In addition, Table 2 shows that most of the articles were published in the form of straight news $(82.2 \%)$, followed by feature articles $(9.9 \%)$, letters-to-the-editor $(6.0 \%)$ and column articles $(1.9 \%)$. Nonetheless, there was no statistically significant difference between the types of articles and number of articles as determined by one-way ANOVA $(\mathrm{F}(2,469)=.944, p=$ $.408)$.

Table 2. Types of Articles Covering Suicide by The Star from 2014-2018

\begin{tabular}{l|c|c|c|c|c|c}
\hline $\begin{array}{l}\text { Types of } \\
\text { Articles }\end{array}$ & $\begin{array}{c}\mathbf{2 0 1 4} \\
(\mathbf{n = 1 7 1}) \\
\mathbf{\%}\end{array}$ & $\begin{array}{c}\mathbf{2 0 1 5} \\
(\mathbf{n = 3 7}) \\
\mathbf{\%}\end{array}$ & $\begin{array}{c}\mathbf{2 0 1 6} \\
(\mathbf{n = 6 1}) \\
\mathbf{\%}\end{array}$ & $\begin{array}{c}\mathbf{2 0 1 7} \\
(\mathbf{n = 7 1}) \\
\mathbf{\%}\end{array}$ & $\begin{array}{c}\mathbf{2 0 1 8} \\
(\mathbf{n = 1 2 9}) \\
\mathbf{\%}\end{array}$ & Mean \\
\hline Straight news & 91.8 & 86.5 & 82.0 & 76.1 & 91.5 & 85.6 \\
Editorial & 0 & 0 & 0 & 0 & 0 & 0 \\
Columns & 2.3 & 13.5 & 3.3 & 7.0 & 0 & 5.2 \\
Features & 0 & 0 & 9.8 & 9.9 & 2.3 & 4.4 \\
Letters & 5.8 & 0 & 4.9 & 7.0 & 6.2 & 4.8 \\
\hline
\end{tabular}

Throughout the timeframe of the study, $61.7 \%$ of the articles reporting suicide portrayed a negative issue image while $37.5 \%$ depicted a neutral image. Only $0.9 \%$ of the articles presented a positive issue image of suicide, and these articles were mainly reporting about advocacy for euthanasia in the US and Spain. One-way ANOVA showed that there was no statistically significant difference between the issue images and the number of articles $[F(4,467)=.694, p$ $=.603]$.

Table 3. Issue Images of Suicide Reported by The Star from 2014-2018

\begin{tabular}{c|c}
\hline Issue Image & Percentage $(\mathbf{n}=\mathbf{4 6 7})$ \\
\hline Negative & 61.7 \\
Positive & 0.9 \\
Neutral & 37.5 \\
\hline
\end{tabular}


More than half of the articles published by The Star (59.3\%) reported suicide cases that happened in Malaysia. International cases contributed to $40.7 \%$ of the coverage on suicide, which mostly involving celebrities, prominent political or business personalities. There was also coverage about how the increased usage of social media by teenagers in the US was linked to cyberbullying and subsequently suicide. In addition, there was news about Netflix's series 13 Reasons Why that had led impressionable viewers to develop suicide-revenge fantasies. According to one-way ANOVA, there was no statistically significant difference between the issue scopes and the number of articles $[F(1,467)=.192, p=.666]$.

Table 4. Issue Scopes of Suicide Reported by The Star from 2014-2018

\begin{tabular}{c|c}
\hline Issue Scope & Percentage $(\mathbf{n}=\mathbf{4 6 7})$ \\
\hline Local & 59.3 \\
International & 40.7 \\
\hline
\end{tabular}

In The Star's coverage of both local and international news on suicide, $21.8 \%$ of the reporting was linked to mental health issues (see Table 5). This was followed by "Others" $(25.5 \%)$, which included problems like sexual abuse, child abuse, substance abuse, poverty, sickness, loneliness in elder people, conflicts with parents and/or siblings, grief and loss, refugee problems, committing suicide to escape punishment, copycat suicide following celebrity's death or television series, as well as lesbian, gay, bisexual, transgender and queer (LGBTQ) problems.

Table 5. Issue Linkages of Suicide Reported by The Star

\begin{tabular}{c|c}
\hline Issue Linkage & Percentage $(\mathbf{n}=\mathbf{4 6 7})$ \\
\hline Mental Health Issues & 21.8 \\
Relationship or Marriage Problems & 8.1 \\
Financial Problems & 3.9 \\
Workplace Stress & 3.9 \\
Academic Pressure & 3.4 \\
Bullying/Cyberbullying & 3.4 \\
Others & 25.5 \\
Not Mentioned & 30.0 \\
\hline
\end{tabular}

Furthermore, suicide coverage by The Star was also linked to relationship or marriage problems $(8.1 \%)$, financial problems $(3.9 \%)$, workplace stress $(3.9 \%)$, academic pressure (3.4\%) and bullying/cyberbullying (3.4). Nevertheless, there was $30 \%$ of suicide coverage by The Star that did not include any issue linkage. There was no statistically significant difference between the issue linkages and the number of articles $[F(7,467)=7.560, p=.000]$ as determined by one-way ANOVA.

The suicide news reported by The Star was mainly following episodic narrative style $(65.3 \%)$. Meanwhile, less than half $(34.7 \%)$ of the suicide coverage adopted a thematic narrative style. According to one-way ANOVA, there was no statistically significant difference between the issue narrative styles and the number of articles $[F(1,467)=.446, p=.513]$.

Table 6. Issue Narrative Styles Used by The Star in Reporting Suicide from 2014-2018

\begin{tabular}{c|c}
\hline Issue Narrative Style & Percentage $(\mathbf{n}=\mathbf{4 6 7})$ \\
\hline Episodic & 65.3
\end{tabular}


More than half of the suicide articles $(60.2 \%)$ in The Star did not discuss a solution for the issue (Table 7). Meanwhile, there was an almost equal percentage of individual and societal responsibility reported in the articles, which was $18.0 \%$ and $19.7 \%$ respectively. There was only $2.1 \%$ of articles that reported an almost equal mix of both individual and societal responsibility. Out of the 467 news articles analyzed, only $15.8 \%$ included help-line at the end of the article. There was no statistically significant difference between the suicide solution and the number of articles $[F(3,467)=1.396, p=.260]$ as determined by one-way ANOVA.

Table 7. Suicide Solutions Advocated by The Star from 2014-2018

\begin{tabular}{c|c}
\hline Suicide Solution & Percentage $(\mathbf{n}=\mathbf{4 6 7})$ \\
\hline Individual Responsibility & 18.0 \\
Societal Responsibility & 19.7 \\
Combination & 2.1 \\
Not Mentioned & 60.2 \\
\hline
\end{tabular}

Table 8 recorded the cross-tabulation between issue narrative styles and solutions advocated by The Star in reporting suicide. In addition, there was a statistically significant association between issue narrative styles and suicide solutions as determined by Pearson ChiSquare test $\left(\mathrm{X}^{2}=160.883, d f=8, p=.000\right)$. While $63.1 \%$ of episodic narrative was leading to individual responsibility, only $36.9 \%$ of thematic narrative was leading to individual responsibility. Also, $84.8 \%$ of thematic narrative was leading to societal responsibility, but only $15.2 \%$ of episodic narrative was leading to societal responsibility.

Table 7. Issue Narrative Styles and Suicide Solutions Advocated by The Star from 2014-2018

\begin{tabular}{c|c|c}
\hline Suicide Solution & $\begin{array}{c}\text { Episodic Narrative } \\
\text { (\% within Solutions) }\end{array}$ & $\begin{array}{c}\text { Thematic Narrative } \\
\text { (\% within Solution) }\end{array}$ \\
\hline Individual Responsibility & 63.1 & 36.9 \\
Societal Responsibility & 15.2 & 84.8 \\
Combination & 10.0 & 90.0 \\
Not Mentioned & 83.9 & 15.7 \\
\hline
\end{tabular}

\section{Discussion}

This study found that there was a statistically significant difference between the number of articles reporting suicide and different years. This reflected that The Star gave an unequal weight of attention to suicide during the time frame of the study, which also reflected the gatekeeping and agenda-setting functions of the newspaper. In addition, most of the coverage was published in the form of straight news, which reported facts or quote references on general information like who, what, when, where, why and how. This descriptive style places the journalist in the role of an observer (Salgado, Stromback, Aalberg \& Esser, 2016). It is important to note that opinion pieces like editorial, column articles, feature articles and letters-to-theeditor offer readers a diversity of interpretation, viewpoints and in-depth analyses from multiple perspectives, hence enhancing the marketplace of ideas and educating public understanding of the issues.

In their discussion about interpretive journalism, Salgado, Stromback, Aalberg and Esser (2016) mentioned that the interpretive style requires the journalist to act as an analyst in addition 
to being an observer. The authors stressed that interpretive journalism aims at finding out the truth behind the facts and statements while educating audiences to understand not only what is happening but also why. More importantly, interpretive journalism is characterized by journalistic explanations, evaluations, contextualization or speculations going beyond verifiable facts or statements by sources. As mentioned earlier, the major drivers of suicide in Southeast Asia include socioeconomic factors such as social inequities, gender disparities, financial strife and family conflicts. Therefore, it takes interpretive journalism to raise the awareness of suicide and to prevent the problem not only through internal, individual or personal effort but also intervention and treatment from various societal, structural, systemic and policymaking levels.

Hjelmeland and Knizek (2016, p. 362) observed that the researchers outside "the West" are more open to understand suicide from a non-biomedical perspective, and more ready to see the contextual issues involved. Notably, the authors alerted that too much focus on mental disorders in suicide prevention may be counterproductive because people might think that there is no danger of suicide for as long as there is no sign of mental disorder. Additionally, associating suicide to mental disorders would attribute a stigmatized image to those with suicidal tendencies, and preventing them from seeking help due to fear of being labelled as mentally ill (Shahtahmasebi, 2015).

Nonetheless, Hjelmeland and Knizek (2017) underscored that it is important to treat mental disorders with regard to suicide prevention. This study also calls for future research to examine the news coverage on mental health as $21.8 \%$ of the suicide reported by The Star was linked to mental health issues. In Malaysia, the 2017 National Health and Morbidity Survey reported that $29 \%$ of the 32 million population in the country suffered from depression and/or anxiety disorder compared to $12 \%$ in 2011 . The survey also reported that suicidal thoughts among teenagers aged 13 to 17 have increased from 7.9\% in 2012 to $10 \%$ in 2017 (Malek, 2019). Scholars have been warning that mental illness is expected to be the second biggest health problem affecting Malaysians after heart disease by 2020 (Chong, Mohamad \& Er, 2013). It is alarming that the cumulative global impact of mental disorders in terms of lost economic output will amount to USD16.3 million between 2011 and 2030 (Word Health Organization, 2020). In Malaysia, the cost of mental health issues in the workplace to the economy is estimated to be RM14.46 billion or 1\% of Gross Domestic Product (GDP) in 2018 to employers (Arumugan, 2020).

A review of literature showed that reporting that portrayed suicide negatively was less likely to be followed by a rise in suicide rates (Gunn, Goldstein \& Lester, 2020). Significantly, Niederkrotenthaler et al. (2010) asserted that reporting that portrayed how people have overcome their suicidal crisis was less likely to be followed by a rise in suicide rates, and this is called the Papageno effect. Although this study found that $61.7 \%$ of the articles reporting suicide portrayed a negative issue image, none of them was undertaking the suicide preventive reporting suggested by Niederkrotenthaler et al. (2010).

Media framing could influence the level of mental health literacy, responsibility attribution and stigma alleviation (Zhang, Jin, Stewart \& Porter, 2016). According to Vishwanath (2014), lack of awareness and knowledge are the reasons for people's negative attributions and stigmatized beliefs. While positive public perceptions could help to promote a sense of acceptance among those facing mental health challenges, negative perceptions may result in individuals feeling rejected or stigmatized. Vishwanath (2014) also alerted that stigmatized perceptions may lead to more problems at a macro level, including a lesser coverage of the problem by media or a lack of funding in an institutional effort to treat or support individuals. Future studies could use the problem characterization and solution advocacy framework employed in this study to further investigate the coverage of mental health issues by media.

Although this study found that episodic framing was the predominant issue narrative style used by The Star in reporting suicide, there was an almost equal percentage of individual and 
societal responsibility advocated by the newspaper. The current study also found a significant difference between issue narrative styles and suicide solutions, which is consistent with the findings of previous studies. Nevertheless, it is worrisome that most of the articles $(60.2 \%)$ did not mention any suicide solution. While this calls for a more robust interpretive journalism, it also points to an area to be investigated by future research. Malaysia is a country with a Muslim majority for whom attempted suicide is a serious breach of the faith (a grievous sin). Furthermore, those who attempt suicide in the country may be prosecuted under Section 309 of the Penal Code. Future studies could examine Malaysian journalist's professional role conception, specifically in studying the factors or challenges affecting journalist's approaches in reporting suicide or even euthanasia. This might provide some insights into the gatekeeping, agenda-setting and framing of suicide coverage. It is hoped that this will also help to explain why most of the articles failed to offer solution for suicide.

\section{Conclusion}

The current study found that The Star gave an unequal weight of attention to suicide during the time frame of the study, which reflected the gatekeeping and agenda-setting functions of the newspaper. Most of the articles were published in the form of straight news and portrayed a negative issue image/attitude towards suicide. The Star also reported both local and international suicide news. In addition, The Star linked suicide issue to contextual factors like sexual abuse, child abuse, substance abuse, poverty, sickness, loneliness in elder people, conflicts with parents and/or siblings, grief and loss, refugee problems, committing suicide to escape punishment, copycat suicide following celebrity's death or television series, as well as lesbian, gay, bisexual, transgender and queer (LGBTQ) problems. Mental health issues were also reported as a major cause for suicide. Although this study found that episodic framing was the predominant issue narrative style used by The Star in reporting suicide, there was an almost equal percentage of individual and societal responsibility advocated by the newspaper. However, the majority of the articles failed to mention responsibility attribution for suicide, which is a severe issue facing the country. The current study also found a significant difference between issue narrative styles and suicide solutions, which is consistent with the findings of previous studies. The current study further extends suicide-framing literature through the exploration of problem characterization and solution advocacy, as well as attribution theory. It also adds value to the study of mediated health communication.

Future studies could look into the interconnection between journalist's professional role conception in reporting suicide, and problem characterization and solution advocacy. This is important because there are practical implications to how media frame suicide, it influences both public perceptions of the need to address this social problem and public support for individual-level or societal-level policies in addressing suicide. Furthermore, further research could analyze the impact of framing suicide as an individual versus societal concern on the audience' response towards societal-level policies to solve the problems.

The findings of this study could provide some suggestions for reporting suicide within the Malaysian context. An interpretive journalism approach, which offers in-depth explanations, evaluations, contextualization or solution could help to convey the complexity of suicide. Subsequently, it could raise awareness of the public, as well as encouraging prevention and intervention effort at an institutional level. In addition, the media could work on including more stories of how individuals have overcome their suicidal crisis to enhance the Papageno effect. Significantly, more coverage should portray suicide as a societal concern to reduce stereotyping of individuals to have gone through the trauma. Media should also report about the vulnerable populations, namely those who experience mental health challenges, sexual abuse, child abuse, 
substance abuse, poverty, sickness, loneliness in elder people, conflicts with parents and/or siblings, grief and loss, refugee problems, as well as lesbian, gay, bisexual, transgender and queer (LGBTQ) problems.

\section{References}

Arafat, S. M., Menon, V., \& Kar, S. K. (2021). Media and suicide prevention in Southeast Asia: challenges and directions. Journal of Public Health 43(1) e123-e124. CrossRef

Arumugam, T. (2020, February 17). Mental health costs Malaysia RM14.46bil or over one percent of its GDP. New Straits Times. Retrieved from https://www.nst.com.my/news/nation/2020/02/566428/mental-health-costs-malaysiarm1446bil-or-over-one-cent-its-gdp

Audit Bureau of Circulations Malaysia. (2019). Newspaper circulation June-December 2018. Retrieved from https://www.abcm.org.my

Barry, C. L., Brescoll, V. L., \& Gollust, S. E. (2013). Framing childhood obesity: How individualizing the problem affects public support for prevention. Political Psychology, 34(3), 327-349. CrossRef

Baumgartner, S. E., \& Wirth, W. (2012). Affective priming during the processing of news articles. Media Psychology, 15(1), 1-18. CrossRef

Brownell, K. D., Farley, T., Willett, W. C., Popkin, B. M., Chaloupka, F. J., Thompson, J. W., \& Ludwig, D. S. (2009). The public health and economic benefits of taxing sugarsweetened beverages. The New England journal of medicine, 361(16), 1599. CrossRef

Bryant, J., \& Miron, D. (2004). Theory and research in mass communication. Journal of Communication, 54(4), 662-704. CrossRef

Chan. L. F., Ibrahim, N., Rahman, N. A. A., Bartlett, S., Ping, N. Y., \& Nordin, A. S. A. (2018). Media Reporting of Suicide in the Era of "Malaysia Baru". Malaysian Journal of Psychiatry, 27(1), 67-73.Chong, D., \& Druckman, J. N. (2007). A theory of framing and opinion formation in competitive elite environment. Journal of Communicatrion, 57(1), 99-118. CrossRef

Chong, S. T., Mohamad, M. S., \& Er, A. C. (2013). The mental health development in Malaysia: History, current issue and future development. Asian Social Science, 9(6), 1. CrossRef

Dahlberg, S., \& Martinsson, J. (2015). Changing issue ownership through policy communication. West European Politics, 38(4), 817-838. CrossRef

Entman, R. M. (1993). Framing: Toward clarification of a fractured paradigm. Journal of Communication, 43(4), 51-58. CrossRef

Gitlin, T. (1980). The whole world is watching: Mass media in the making \& unmaking of the new left. Berkeley: University of California Press.

Goffman, E. (1974). Frame analysis: An essay on the organization of experience. Cambridge: Harvard University Press.

Gounder, F., \& Ameer, R. (2018). Defining diabetes and assigning responsibility: how print media frame diabetes in New Zealand. Journal of Applied Communication Research, 46(1), 93-112. CrossRef

Gunn, J. F., Goldstein, S. E., \& Lester, D. (2020). The impact of widely publicized suicides on research trends: Using Google trends to test the Werther and Papageno effects. Archives of Suicide Research, 24(2), 142-155. CrossRef

Guo, L., \& Vargo, C. (2015). The power of message networks: A big-data analysis of the network agenda-setting model and issue ownership. Mass Communication and Society, 18(5), 557-576. $\underline{\text { CrossRef }}$ 
Halladay, J. E., Munn, C., \& Boyle, M. (2020). Temporal changes in the cross-sectional associations between cannabis use, suicidal ideation, and depression in a nationally representative sample of Canadian adults in 2012 compared to 2002. The Canadian Journal of Psychiatry, 65(2), 115-123. CrossRef

Heider, F. (1958). The psychology of interpersonal relations. New York: Wiley.

Hernandez-Aquado, I., \& Chilet-Rosell, E. The role of the media in the health policymaking process: Perspectives of key actors in Spain. Journal of Critical Health, 30(3), 270-279. CrossRef

Hjelmeland, H., \& Knizek, B. L. (2016). Qualitative evidence in suicide: Findings from qualitative psychological autopsy studies. In Handbook of qualitative health research for evidence-based practice (pp. 355-371). New York: Springer.

Hjelmeland, H., \& Knizek, B. L. (2017). Suicide and mental disorders: A discourse of politics, power, and vested interests. Death Studies, 41(8), 481-492. CrossRef

Holling, M. A. (2019). Rhetorical contours of violent frames and the production of discursive violence. Critical Studies in Media Communication, 36(3), 249-271. CrossRef

Indramalar, S. (2018, June 13). Tackling anxiety and depression. The Star. Retrieved from https://www.thestar.com.my/news/nation/2018/10/20/tackling-anxiety-anddepression-experts-these-are-the-most-common-illness-workers-face-now/

Iyengar, S. (1990). Framing responsibility for political issues: The case of poverty. Political Behavior, 12(1), 19-40. CrossRef

Iyengar, S. (1996). Framing responsibility for political issues. The Annals of the American Academy of Political and Social Science, 546(1), 59-70.

Iyengar, S. (2005). Speaking of values: The framing of American politics. The Forum, 3(3), 18. CrossRef

Jenkin, G. L., Signal, L., \& Thomson, G. (2011). Framing obesity: the framing contest between industry and public health at the New Zealand inquiry into obesity. Obesity Reviews, 12(12), 1022-1030. CrossRef

Jenkin, G. L. S., Slim, B. E., \& Collings, S. (2020). News media coverage of stakeholder views on suicide and its reporting in New Zealand. Crisis: The Journal of Crisis Intervention and Suicide Prevention, 41(4), 248-254. CrossRef

Johari, M. A., Shukri, M. Z. M., Abd, M. A. S., Karim, M. H. H. I., Khazali, A. K., Nasarudin, A. A., ... \& Razali, S. (2017). Perception of media in reporting suicide cases in Malaysia. Akademia Baru. Journal of Advanced Research in Social and Behavioural Sciences, 7(1), 59-67.

Kelley, H. H. (1967). Attribution theory in social psychology. In D. Levine (Ed.), Nebraska symposium on motivation (pp. 192- 240). Lincoln: University of Nebraska Press.

Kim, S. H. (2015). Who is responsible for a social problem? News framing and attribution of responsibility. Journalism \& Mass Communication Quarterly, 92(3), 554-558. CrossRef

Liu, X. S., Robinson, S., \& Vedlitz, A. (2016). Public problem characterization, policy solution generation, and intra-agenda connectivity. The Policy Studies Journal, 44(4), 396-423. CrossRef

Liu, Y., Cui, C., Zhang, C., Xia, B., Chen, Q., \& Skitmore, M. (2020). Effects of economic compensation on public acceptance of waste-to-energy incineration projects: an attribution theory perspective. Journal of Environmental Planning and Management, Published online: 25 Nov 2020 CrossRef

Malek, N. H. (2019, December 4). Malaysia's 1st mental health handbook launched. The Malaysian Reserve. Retrieved from https://themalaysianreserve.com/2019/12/04/malaysias-1st-mental-health-handbook- 
launched/Manheim, J. B. (1994). Strategic public diplomacy and American foreign policy: The evolution of influence. New York: Oxford University Press.

McGlynn, J., \& McGlone, M. S. (2018). Desire or disease? Framing obesity to influence attributions of responsibility and policy support. Health Communication, 34(7), 689701. CrossRef

Naab, T. K., Heinbach, D., Ziegele, M., et al. (2020) Comments and credibility: How critical user comments decrease perceived news article credibility. Journalism Studies, 21(6), 783-801. CrossRef

Niederkrotenthaler, T., Voracek, M., Herberth, A., Till, B., Strauss, M., Etzersdorfer, E., ... \& Sonneck, G. (2010). Role of media reports in completed and prevented suicide: Werther v. Papageno effects. The British Journal of Psychiatry, 197(3), 234-243. CrossRef

Pandiyan, M. V. (2020, January 8). Smash the stigma, stop the suicides. The Star. Retrieved from $\quad$ https://www.thestar.com.my/opinion/columnists/along-thewatchtower/2020/01/08/smash-the-stigma-stop-the-suicides

Papacharissi, Z., \& de Fatima Oliveira, M. (2008). News frames terrorism: A comparative analysis of frames employed in terrorism coverage in US and UK newspapers. The International Journal of Press/Politics, 13(1), 52-74. CrossRef

Petticrew, M., Eastmure, E., Mays, N., Knai, C., Durand, M. A., Nolte, E. (2013). Public health responsibility deal: How should such a complex public health policy be evaluated? Journal of Public Health, 35(4), 495-501. CrossRef

Reese, S. D., Gandy Jr, O. H., \& Grant, A. E. (Eds.). (2001). Framing public life: Perspectives on media and our understanding of the social world. New York: Routledge.

Salgado, S., Stromback, J., Aalberg, T., \& Esser, F. (2016). Interpretive journalism. In C. De Vreese, F. Esser, \& D. N. Hopmann (Eds.), Comparing political journalism (pp. 5070). New York: Routledge.

Scammell, M., \& Semetko, H. (2018). The media, journalism and democracy. New York: Routledge.

Scheufele, B. (2004). Framing-effects approach: A theoretical and methodological critique. Communications, 29(4), 401-428. CrossRef

Scheufele, B., \& Scheufele, D. A. (2010). Of spreading activation, applicability, and schemas conceptual distinctions and their operational implications. In P. D'Angelo \& J. A. Kuypers (Eds.), Doing news framing analysis: Empirical and theoretical perspectives (pp. 110-134). New York: Routledge.Scheufele, D.A., \& Tewksbury, D. (2007). Framing, agenda setting, and priming: The evolution of three media effects models. Journal of Communication, 57(1), 9-20. CrossRef

Shahtahmasebi, S. (2015). Suicide research: Problems with interpreting results. Journal of Advances in Medicine and Medical Research, 5(9), 1147-1157. CrossRef

Starr, T. S., \& Oxlad, M. (2020). News media stories about cancer on Facebook: How does story framing influence response framing, tone and attributions of responsibility? Health. (First Published March 18, 2020) CrossRef

Sun, Y., Krakow, M., John, K. K., Liu, M., \& Weaver, J. (2016). Framing obesity: How news frames shape attributions and behavioral responses. Journal of Health Communication, 21(2), 139-147. CrossRef

Tankard, J. W., Jr., Hendrickson, L., Silberman, J., Bliss, K. A., \& Ghanem, S. (1991, August). Media frames: Approaches to conceptualization and measurement. Paper presented to Association for Journalism and Mass Communication, Boston. Tuchman, G. (1978). Making news: A study in the construction of reality. New York: Free Press.

Turosak, A., \& Siwierka, J. (2021). Mental health and stigma on campus: Insights from students' lived experience. Journal of Prevention \& Intervention in the Community. 49:3, 266-281. $\underline{\text { CrossRef }}$ 
Victor, J., Heng, J. G. K., Govindaraju, G. M., Tan, P. L., Rajaratnam, U., \& Yang, L. F. (2019). Media reporting of suicide: A comparative framing analysis of Malaysian newspapers. SEARCH Journal of Media and Communication Research, 11(2), 23-49.

Vishwanath, A. (2014). Negative public perceptions of juvenile diabetics: Applying attribution theory to understand the public's stigmatizing views. Health Communication, 29(5), 516-526. CrossRef

von Sikorski, C. (2020). Integrative framing analysis: Framing health through words and visuals. New York: Routledge.

Wallace, L. N. (2019). US beliefs about the causes of terrorism: An application of attribution theory. Communication Studies, 70(5), 654-676. CrossRef

Weiner, B. (1979). A theory of motivation for some classroom experiences. Journal of Educational Psychology, 71(1), 3-25. CrossRef

Weiner, B. (1995). Attribution theory in organizational behavior: A relationship of mutual benefit. In Martinko M. J. (Ed.), Attribution theory: An organizational perspective (pp. 3-6). Boca Raton: St. Luicie Press.

Wichgers, L., Jacobs, L., \& van Spanje, J. (2020). The battle of frame building: The reciprocal relationship between journalists and frame sponsors. The International Journal of Press/Politics. (First Published August 6, 2020) CrossRef

Wikler, D. (2002). Personal and social responsibility for health. Ethics \& International Affairs, 16(2), 47-55. CrossRef

Wimmer, R. D., \& Dominick, J. R. (2013). Mass media research: An introduction. Boston: Wadsworth.

Wood, M. L., Stoltz, D. S., Van Ness, J., \& Taylor, M. A. (2018). Schemas and frames. Sociological Theory, 36(3), 244-261. CrossRef

World Health Organization. (2017). Suicide prevention. Retrieved from https://webprod.who.int/news-room/fact-sheets/detail/suicide

World Health Organization. (2020). Depression. Retrieved from https://www.who.int/newsroom/fact-sheets/detail/depression

Yang, L. F. (2020). The framing of the Chinese ambassador's visit to Malaysia's Chinatown: A gesture of goodwill or interference in domestic politics? Journalism (First Published September 21, 2020) CrossRef

Zhang, Y., Jin, Y., Stewart, S., \& Porter, J. (2016). Framing responsibility for depression: How US news media attribute causal and problem-solving responsibilities when covering a major public health problem. Journal of Applied Communication Research, 44(2), 118135. CrossRef

Zolkepli, F. (2020, January 1). Move to decriminalize suicide long overdue, says Lam Thye. The Star. Retrieved from https://www.thestar.com.my/news/nation/2020/01/01/moveto-decriminalise-suicide-long-overdue-says-lam-thye 